\title{
Managing suicidal patients in clinical practice
}

\author{
Angelo De Gioannis, Diego De Leo \\ Life Promotion Clinic, Australian Institute for Suicide Research and Prevention, WHO Collaborating Centre on Research and \\ Training in Suicide Prevention, Griffith University, Mount Gravatt Campus, Brisbane, Australia \\ Email: d.deleo@griffith.edu.au
}

Received 28 September 2011; revised 26 October 2011; accepted 12 November 2011

\begin{abstract}
The clinical management of suicidal patients can be very challenging. This paper guides the reader through the basic steps in assessing a subject and deciding the type of treatment to provide. Characteristics of main psychiatric pathologies associated with suicidality are described, with attention to the peculiarities that specific associations may frequently entail.
\end{abstract}

Keywords: Clinical Management; Suicidal Patient; Community Environment; Private Practice; Risk Factors; Treatment

\section{INTRODUCTION}

Assessing or treating a suicidal patient represents probably the most challenging task clinicians have to face in their professional life, both intellectually and emotionally. Not many clinical interactions generate emotional responses quite as intense as dealing with an individual who has recently survived a serious suicide attempt or is contemplating a fatal act in the near future. There are multiple reasons behind these responses. Firstly, as clinicians we have been trained to objectively and systematically assess symptoms and signs of illness in order to reach a sound diagnosis. On the basis of this diagnosis-whether provisional or confirmed-we have the responsibility of formulating and evaluating an effective treatment plan. In the case of suicidality, what we are often faced with is not a diagnosable illness but a behaviour to which many different psychiatric illnesses of various severities may contribute. In some cases, no detectable psychiatric illness is present. Secondly, as clinicians we have been invested with the responsibility of ensuring the well being of our patients and, as much as possible, to avert complications arising from illnesses. In recent times, clinicians have experienced an increasing level of scrutiny into the validity of the diagnoses attributed to patients and the effectiveness of the treatment strategies implemented. The threat of litigation has greatly affected the way clinicians approach clinical interactions with their patients. As a result, being able to manage the countless issues sur- rounding the assessment and management of individuals presenting with suicide risk represents one of the fundamental skills clinicians have to develop and preserve throughout their professional life. In this article, we will attempt to describe and clarify the most salient aspects of dealing with suicidality in every-day clinical practice.

\section{DEFINITIONAL ISSUES}

The first obstacle faced in approaching the suicidal patient is certainly how to appropriately define the behaviour we are about to assess. In recent years, there has been considerable debate surrounding the validity of current definitions, in particular for what relates to our ability to differentiate suicidal behaviour from self-harm behaviour without suicide intent $[1,2]$. In this chapter the term "suicidal" will be used to describe any behaviour or ideation involving harm to self irrespective of the level of intent to die. The reason for approaching the subject from this stance is two-fold. On one hand, as stressed by [3], the motives behind self-injurious behaviours and suicidal ideation are sometimes so difficult to establish that clinicians will never be in the position to exclude suicide intent unequivocally [4]. The other consideration to be made is that despite the many differences observed between individuals with self-harm and suicidal behaviour, the absence of reported suicidal intent is not sufficient to exclude the risk of completed suicide. On the contrary, the presence of self-injurious behaviour significantly increases the risk of suicide later in life. In a recent cohort study of individuals presenting to an emergency department following self-harm, the authors found that in the 4-years following presentation the rate of completed suicide was 30 times greater than the one expected in the general population [5]. In addition, mental health clinicians should be aware of the frequent fluctuations in suicidality individuals may manifest, these ranging from death wishes to completed suicide, with intervals free from any suicide ideation $[6,7]$.

\section{EPIDEMIOLOGICAL DIMENSION}

Before delving into the clinical aspects of suicide, it is 
important to make it clear that suicidal behaviour cannot be fully understood if interpreted only as a consequence of psychiatric illness. In fact, suicidal behaviour is a multifactorial event, extending beyond the psychiatric or psychopathological realm of human experience.

The global mortality rate from suicide in 2000 was $16 / 100,000$, with approximately one million individuals taking their life that year. For countries that report mortality data to the World Health Organization (WHO), the rate of suicide has increased by $60 \%$ over the last 45 years [8], with suicide being represented in the top ten leading causes of death for all ages, but in the top three for the age group of 15 - 34 years [8]. Sadly, for every completed suicide at least six other people related to the deceased remain deeply affected [9].

“Attempted suicides" (non-fatal suicidal behaviours) are estimated to be up to 20 times as frequent as suicide [6]. Data on the incidence of suicide ideation is unfortunately not as reliable as we would hope, but we have some information regarding the number of people contemplating suicide during their lives. In a recent international multi-centre community survey study, up to $25 \%$ of the interviewees reported having contemplated suicide during their life, with up to $15 \%$ going as far as planning a suicide act. It is also worth considering that in the same study, between $0.4 \%$ and $4.2 \%$ of the people surveyed reported at least one suicide attempt during their life [10].

\section{RISK ASSESSMENT}

Without a doubt, the most important clinical tool psychiatrists require in approaching a suicidal patient is the ability to conduct an efficient and effective risk assessment. In this procedure, the various aspects of patients' demographic data and personal and family history are translated into risk or protective factors on the basis of what available research data reveal. The ultimate objective of the interview is to transform the information gathered into a statement that includes the overall level of risk for that individual. In doing that, we have to remember that the amount and reliability of the information we obtain during a risk assessment will be closely related to the strength of the therapeutic relationship with the patient we are interviewing: the longer the relationship (and the therapeutic alliance), the higher the probability of a positive impact on the outcomes.

Before going any further, it is important to understand that a risk assessment is in no way a tool we can utilize to predict suicide. Unfortunately, even the most comprehensive risk assessment performed will only be useful to gauge the level of risk for that particular individual at that particular time. In fact, while some risk and protective factors do not change over time, many others do, with a significant influence on the choices clinicians have to make in managing patients. This means that a patient's risk assessment has to be regularly revised and adjourned to reflect the developments in the individual's clinical presentation, life circumstances and treatment, if implemented [11]. In recent years, a number of professional bodies have published and regularly updated practice guidelines for the assessment and management of individuals at risk of suicide, such as those produced by the National Institute for Clinical Excellence [12], the American Psychiatric Association [13], and the American Academy of Child and Adolescent Psychiatry [14].

\section{UNMODIFIABLE RISK FACTORS}

In assessing risk, we soon realize that some of the variables we observe during the interview are beyond our control. For example, there are a number of demographic variables that have a strong correlation with suicide rates. One of the most significant is gender. In fact, even though women are more likely to be admitted to a hospital following a suicide attempt, men complete suicide in considerably greater numbers, with around three to four men completing suicide for every woman [15]. These differences appear to have been consistent over time and apart for very few exceptions, consistent across cultures [15]. A number of variables have been hypothesized as linked to this discrepancy (the "gender paradox"): men appear to choose more lethal methods; they are more likely to manifest impulsive behavior, and to abuse substances. Moreover, men are much less prone to seeking help if in need $[7,16]$.

Among demographic data, we also find age as a significant variable needing consideration when assessing risk. In fact, suicide rates steadily increase with age, to reach the level of 50/100,000 in the male elderly group as represented in Figure 1, which refers to the average rate of suicide in the world.

As also noted in the figure, whereas suicide rate for women shows a gradual increase with age, men' suicide rate first peaks in middle adulthood, showing a marginal decline until the dramatic increase for the 75+ group [17]. Marital status is another important factor to be carefully examined even if, because of barriers in collecting reliable data, it appears to have been researched less than the risk factors discussed so far. Despite this, there is sufficient evidence to suggest a link between relationship status and suicidal behaviour. In general, research supports a positive association between being single and suicide rates. The association appears stronger if we consider divorce and-especially-separation $[18,19]$. A study found separated men to be about six times more likely to die from suicide than their married counterpart [20]. The impact of being single or separated on suicide rates is for men far greater than for women [18]. It has been suggested that in women the effect of being single or separated is mitigated by the protective role of parenthood, 
Distribution of suicide rates (per 100,000)

$$
\text { by gender and age, } 2000
$$

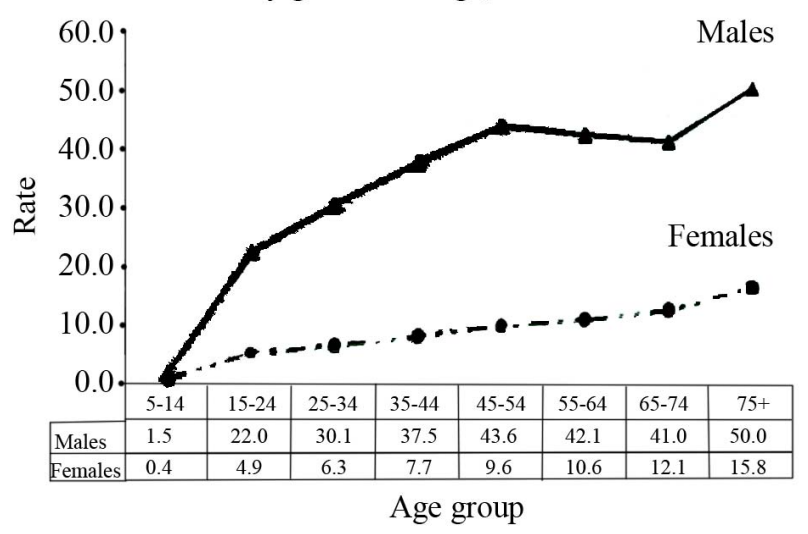

Figure 1. Average suicide rates in the world [17].

which has been found to be stronger in female subjects [21]. Also, women would generally benefit from far greater social networks than men, and this would offer both support for emotional ventilation and opportunity for new relationships [19].

Beyond demographic characteristics, suicide risk will also be affected by the genetic make-up. For example, it has been observed that the risk of suicide in individuals with family history of suicide is twice bigger than in the general population, independently from the presence of severe mental illness [22]. Secondly, the improvement of genetic modeling has allowed confirming that adopted individuals who complete suicide are more likely to have a family history of suicide among their biological relatives. Again, the impact of genetic predisposition was independent from psychiatric disorders commonly associated with suicide [23].

It is beyond the scope of this article to discuss all possible risk factors linked to an increased likelihood of suicide in the individuals we assess and treat (Table 1). Our objective is primarily to alert clinicians about the fact that suicide risk assessment requires flexibility and constant adaptability in our perspectives during the interview. Many different and multifaceted aspects of human experience have to be taken into account to carry out a thorough suicide risk assessment; if we do not maintain a "wide open angle" in our examination, we run the risk of becoming excessively focused on a partial view of the individual's own experience, thus losing our ability to perform a valid evaluation.

Having considered some of the demographic and biological variables impacting on the level of risk, we now come to examine probably the most significant group of unmodifiable risk factors clinicians cannot afford to ignore. A history of attempted suicide, suicide ideation or even having been hospitalized for a major mental illness
Table 1. Risk factors associated with increased suicide risk.

Demographic factors
Male gender
Single
Separated/Divorced
Widow/er
Elderly
Adolescent
Gay, lesbian (“discovery” time)
Suicidal thoughts/behaviours
Suicidal ideation
Suicidal plan
Previous suicide attempt
Severity of previous attempt
Lethality of suicide plan
Suicide intent
Psychiatric hospitalisation/recent discharge

\section{Mental illness}

Major depressive disorder

Bipolar affective disorder

Schizophrenia

Anorexia nervosa

Alcohol abuse disorder

Cluster B personality disorders

Psychiatric co-morbidity

\section{Psychological factors}

Hopelessness

Panic attacks

Severe anxiety

Aggression and impulsivity

\section{Genetic factors}

Family history of mental illness

Family history of suicide

\section{Traumatic childhood}

Sexual abuse

Physical abuse

Emotional neglect

\section{Psychosocial factors}

Unemployment

Public humiliation

Divorce

Loss of support

Stressful life event

Access to lethal means

Adapted from De Leo \& Krysinska, 2008 [24].

significantly exposes individuals to an increased risk of suicidal behaviour. An overwhelming amount of research data confirms the magnitude of the impact those factors have on our ability to predict future behaviour. For example, around $5 \%$ of individuals who attempted suicide 
were found to complete suicide within 10 years [25]. Not only previous history of suicide attempts should raise the level of clinical alert, but also individuals' past history of suicide ideation. [26], in a population of outpatients, measured the level of suicide ideation at the time of presentation and the severity of the suicide ideation when at its worst in the life span. The authors found that past suicide ideation was a far better predictor of future suicide than the level of suicide ideation at the time of assessment, with odds ratios of 13.85 vs 5.42 . More recently, a great deal of attention has also been focused on the relationship between hospitalization and suicide risk. Dramatic changes have occurred over the last 30 years in the way mentally ill individuals are treated, with a significant shift in the emphasis placed on the utilization of hospital/inpatient treatment [27]. We need to be mindful of the fact that several studies have established a clear relationship between suicide and certain aspects of hospital treatment. Firstly, suicide is highest the first few days following hospital admission and the first few days following discharge. Secondly, suicide risk increases along with number of admissions to an inpatient facility [28, 29]. There is much speculation over the reasons for such relationships, which are extremely relevant to 'front line' psychiatrists, often the only clinicians involved in the decision over whether to admit or discharge an individual at risk of suicide. We are used to think that hospital treatment represents the best way to avert suicide when individuals are considered to be at high risk. Unfortunately, in many occasions the hospital environment is inadequate to appropriately support the suicidal patient, Moreover, the stigma attached to psychiatric hospitalisation often hinders the process of recovery. The result is, in some cases, that the suicidal person perceives the prospect of a hospital admission as the "last straw", paradoxically facilitating suicide completion. Actually hospitalisation should always be seen as one of the components of a sound and well thought out management plan, and not as an easy way to prevent suicide or speed up the healing process [30].

\section{MODIFIABLE RISK FACTORS}

Modifiable risk factors are those factors we as clinicians can have some impact on. The same way as for the unmodifiable risk factors, we will only concentrate on those we cannot afford to ignore in any circumstance.

Needless to say, any form of suicide ideation is regarded as clinically important, and as such requiring the utmost diligence in assessing the nature and the extent of the suicidal thoughts. As mentioned above, individuals who present with suicide ideation are more likely to complete suicide regardless of the nature and severity of the mental illness they suffer from [26]. Very often individuals perceive those thoughts as distressing, but be- cause of the stigma attached to suicidality, they may not be as forthcoming as we would hope. That is why a careful and tactful exploration of patients' suicide ideation requires considerable skills and experience, in particular with specific populations such as the elderly and the adolescents. It is important to stress that exploring suicide ideation does not to increase patients' risk of suicide. In fact, frequently patients find comfort in being able to discuss their struggle and ventilate their self-destructive thoughts. In the evaluation of patients' level of ideation, it is essential to investigate the presence of any intent to act on those thoughts and even more any plans enabling the patients to perform the act. Moreover, it is the clinician's responsibility to carefully explore the availability of lethal means to carry out the suicidal act and ensure steps are taken to limit access to them. It cannot be stressed enough that the more detailed the suicide plan, the higher the risk of suicide. However, it is also important to consider that, in many cases, individuals who have a high level of intent may be reluctant to disclose any information that could lead to their suicide plans being hindered.

Of all risk factors for suicide that have been considered so far, researchers have identified mental illness as the most significant. Over $90 \%$ of individuals completing suicideare affected by at least one mental illness, with depression as the most commonly reported (at least in $30 \%$ of cases). Substance abuse disorders are also frequent $(17.6 \%)$, as well as schizophrenia (14.1\%), and personality disorders (13.0\%) [31]. Lifetime risk of suicide in psychiatric illnesses such as depression, schizophrenia and alcohol use disorder is reported to be around $5 \%-15 \%$ [31]. It is also important to consider that even though a significant number of individuals who die from suicide have never had any medical contact, between $40 \%$ and $60 \%$ have seen a clinician in the month preceding suicide [32]. Especially in the western world, the relationship between suicide risk and mental illness is so strong that no prevention strategy would succeed without effective treatment of the disorder individuals present with $[33,34]$.

\section{PROTECTIVE FACTORS}

A risk assessment cannot be considered complete until both risk and protective factors are carefully evaluated. It has been well established how some factors such as responsibility to family and children, religiosity and social support can have a positive impact on suicide rates [35]. A self-report questionnaire, the Reasons for Living Inventory, has been found useful in clinical practice to document the presence of possible preventive factors [36]. Among the protective factors explored by researchers over the years, therapeutic alliance is probably one of the most relevant to us as clinicians [37]. Regardless the na- 
ture of the treatment offered, the interview with a suicidal individual requires the psychiatrist to make every possible effort to build trust and a sense of co-operation. It is only when sufficient mutual respect is established that the patient's experience can be fully explored and a reliable assessment carried out. Empathy is still one of the most powerful tools clinicians can utilize in caring for suicidal individuals. However, it may be difficult to maintain a sufficient level of empathy when our therapeutic efforts are contrasted by the need to ensure the safety of our patients [38].

\section{INTEGRATING THE INFORMATION}

To this date, there is no recognized tool able to reliably predict suicide. The only certainty is that all clinicians are expected to perform a competent risk assessment, no matter what the circumstances leading to the assessment are [39]. To facilitate a productive interviewing, we need to provide a safe and comfortable environment. In fact, where the interview is performed will have a significant impact on the outcome. A suitable room should be selected to ensure that confidential and emotionally sensitive information could be comfortably disclosed to the clinician without the risk of distraction or intimidation. As much as possible, the clinician should put in place measures to be able to dedicate to the patient the time required for the assessment without interruptions (and, helas, sometimes this time is well beyond the hour!). In preparing for a risk assessment, it is important to ensure that the mental and physical state of the patient are compatible with the interview that is about to be undertaken.

Besides information deriving from the interview with the suicidal person, itself, a sound risk assessment could benefit from the availability of a "collateral" history. Frequently, it is on the basis of information disclosed by partner or spouse, relatives or friends that individuals first come to the attention of clinicians. Despite this, just as often we fail to seek or acknowledge the invaluable information significant others can provide. In fact, on many occasions the collateral history we obtain will be the only reason for deeming the patient at high risk and initiating treatment. Common examples of this case scenario are patients who purposefully conceal their suicide intent and plan, or those who are affected by mental illness so severe that they are unable to divulge their thoughts and feelings in an understandable way.

There is yet another important task clinicians have to master in modern day practice, which is the one of thoroughly documenting the information gathered. It goes without saying how essential it can be for a psychiatrist or a mental health service to have sufficient information in the clinical file in the case of litigation or scrutiny [40]. Moreover, in current times it is most unusual for a pa- tient presenting to a mental health service to receive psychiatric care from a single clinician. Usually, several doctors and mental health professionals become involved —in different ways and at different stages - in the management process. As a result of this, each clinicians has the added responsibility to communicate as effectively as possible the information collated and what has been done up to that point to avoid unnecessary delays or omissions.

\section{THE DEPRESSED PATIENT}

Depressive illnesses affect around 5\% of the population. The risk of completed suicide has been unequivocally linked to depression in its various forms [31]. An estimate of the suicide risk in a population presenting with mood disorders compared to the general population was 20-fold for major depression, 15-fold for bipolar disorder and 12-fold for dysthymia [41]. More recent studies have confirmed the role of depression as a precursor of suicide, especially when protracted and refractory to treatment [42]. In the assessment of a depressed individual, hopelessness requires special consideration. Its significance is not only related to its diagnostic value but also as the expression of emotional turmoil individuals experience, regardless of the specific illness being treated. In fact, a significant number of studies have confirmed a close relationship between the experience of hopelessness and suicide risk independently of the severity of the illness itself [43]. So much so, that the Beck Hopelessness Scale is still one of the most commonly used and valued psychometric tools utilized in clinical practice [44]. As mentioned above, suicide risk is significantly high in bipolar disorder, where episodes of depression alternate with episodes of mania of varying frequency and severity. Even though suicidal behaviour can occur during a period of mania, the vast majority of completed suicides in individuals with bipolar disorder have been found to occur during a depressive episode [45].

\section{THE SCHIZOPHRENIC PATIENT}

Schizophrenia is one of the most severe and disruptive mental illnesses, affecting around $0.5 \%-1 \%$ of the population. It is characterised by impairment in perception, cognition, and social and occupational functioning. Patients typically manifest a varying combination of positive and negative symptoms requiring ongoing antipsychotic treatment. The lifetime suicide risk for individuals with schizophrenia has historically been quoted at around $10 \%$ of affected individuals. [46] have recently challenged that notion and estimated that risk at about 5\%, also finding most of the suicides to occur in the period following the illness onset. In the case of schizophrenia, it is well recognised that the older the patient, the smaller the risk of suicide. The rate of suicide in schizophrenia is 
influenced by some factors that are illness specific. It has been found that factors such as motor restlessness fear of mental disintegration and poor adherence to treatment impact on the rate of suicide just as much as more general factors like depressive illness or previous suicide attempts [47]. It is also important to stress again how the risk of suicide in schizophrenia peaks in the first few days following admission to hospital and following discharge. Even though we institute treatment as effectively as we can, with the best of intentions, the process of hospitalisation can be extremely traumatic. In the same way, the period after discharge can be particularly difficult, especially in terms of adjusting to life with a newly diagnosed illness that carries little prospects of satisfactory recovery and strong stigmatization from community members. Monitoring of mental state and compliance enhancing strategies are particularly important in this population.

\section{THE SUBSTANCE ABUSER}

Substance abuse (alcohol abuse in particular) represents a social phenomenon with significant repercussions on people's physical and mental health. In regard to suicide risk, alcohol abuse is considered second only to depresssion as a precursor to completed suicide [48]. The lifetime risk of suicide in alcoholics varies considerably depending on the reporting habits and the overall rate of suicideof the country involved, but it is estimated to be around 3\% [49]. Most attempted and completed suicides in alcoholics appear to be related to a depressive episode, stressful live event, loss of support or disruption of interpersonal relationships [50]. The impact substances have on patients' level of rationality and impulsivity makes the assessment of suicide risk all but secondary in the management of substance abuse.

\section{THE PERSONALITY DISORDERED PATIENT}

Personality disorders are defined as enduring, inflexible and pervasive patterns of behaviour and inner experience that seriously deviate from cultural norms and cause significant distress or impairment in various areas of individuals' functioning [13]. Of the various personality disorders known in clinical practice, the most frequently encountered in most settings is certainly Borderline Personality Disorder, which features suicidality and self-injurious behaviour as essential criteria of illness. Individuals affected by one or more personality disorders attempt and complete suicide just as much as individuals diagnosed with a depressive illness [51]. In fact, a review of psychological autopsy studies revealed that around $57 \%$ of individuals who had completed suicide had a diagnosis of personality disorder [52]. Moreover, perso- nality disorders have been found to represent the second most common diagnosis after adjustment disorder in a population of suicide attempters [53]. The difficulty in fully appreciating the impact personality disorders have on suicidality is the fact that they very often coexist with other mental illnesses [54]. Moreover, the presence of one or more personality disorders represents a significant challenge for clinicians and mental health services, both because of the disruptive behaviours they often manifest and because of the permanent nature of the disorder.

\section{THE ANXIOUS PATIENT}

Anxiety disorders represent the most common group of mental illnesses in the community, with almost $30 \%$ of the population affected by at least one of these disorders at some point in their life [55]. Even though trait anxiety is often reported as one of the factors increasing suicide risk, anxiety disorders have never been seen as independent risk factors for completed suicide. However, a recent review found that some anxiety disorders may increase suicide risk, especially when associated with other mental illnesses such as depression, bipolar disorder, or schizophrenia [56]. In view of this, it is essential to make every possible effort to treat any anxiety disorder individuals present with, also considering that their response to psychiatric interventions is often much better than for other mental illnesses.

\section{THE ADOLESCENT PATIENT}

Completed suicide represents the third leading causes of mortality in the adolescent population [8] Just under 15\% will self harm and up to $45 \%$ report suicidal ideation during their life [47]. More than the adult population, adolescents are vulnerable to the effects of relationship breakdown, and physical, sexual and emotional abuse [57,58]. Most studies highlight how adolescents who attempt suicide show reduced distress tolerance skills and poor mood regulation [14]. Moreover, adolescents manifest higher levels of impulsivity and aggression compared to their adult counterpart with a significant impact on the likelyhood of self-destructive behaviours [59]. In an attempt to facilitate the assessment and treatment of adolescents presenting with suicidal behaviour [14] have developed practice guidelines to support clinicians in their effort to reduce the likelihood of completed suicide in this very vulnerable population.

\section{THE ELDERLY PATIENT}

The elderly population is probably the one presenting with the most challenges for mental health clinicians [60]. As already highlighted, men over 75 years of age carry the highest suicide rate of all, and have done that consistently for a long time. At the same time, the elderly po- 
pulation will be the most likely to have been seen by a medical practitioner in the month preceding their completed suicide. A number of factors make detection and management of suicide risk extremely difficult [61]. The most significant risk factors for suicidal behaviour identified in the elderly population are in fact factors such as physical illness, social isolation, relationship problems, and bereavement or loss [62]. As one can appreciate, it would be extremely difficult to identify at risk individuals on the basis of almost universal problems present in this population, like those listed above [63].

\section{TREATMENT}

If the assessment of suicide risk can be perceived at times as challenging and overwhelming, the treatment of individuals at risk of suicide represents for clinicians a real test of psychological strength. In fact, managing suicidal individuals is often emotionally taxing to the point of deterring some clinicians from accepting referrals involving suicide risk. Unlike other medical disciplines, death is not generally acknowledged as a possible complication of illness in mental health. To cope with the increased sense of pressure, mental health clinicians often become vulnerable to counter-transference reactions that instead of facilitating treatment progress create more angst and anxiety. Rescue fantasies and attempts to reparent patients are only examples of the many forms counter-transference can take [64]. Effective anxiety management and consistent supervision are imperative for any clinician intending to venture into this treacherous field of medicine.

\subsection{The Setting}

The management of suicide risk includes a vast number of both biological and psychosocial approaches that can be utilised at different stages of the treatment process. However, the first important decision to be made is the selection of the setting in which the patient is going to receive the treatment. It is often difficult to ensure the safety of the patient, whilst at the same time minimising disruption to their already arduous lives [65]. Without a doubt, inpatient treatment allows clinicians the constant monitoring of suicide risk, mental state and response to treatment, and most important of all, visual observation of the patient at all times. However, clinicians soon realise that it is unrealistic, and in some cases unreasonable, to rely on segregation as a cure for suicide risk. Often suicide risk is increased by financial, interpersonal and occupational stressors, and removing individuals from their familiar environment can only add to the stress they experience in trying to address the difficulties at hand. Furthermore, every time we admit a patient to hospital and increase the level of supervision by clinical staff, at the same time we also cause the suicidal individual to lose significant support they would otherwise get in the community. In fact, a significant protective factor for suicide is interpersonal connectedness, particularly for women with children, which we invariably disrupt whenever we opt for inpatient treatment. As a result, hospital treatment should be thought of as one of the possible options available, and not as a quick fix to the problem of suicide risk. Every possible attempt should be made in trying to implement treatments that acknowledge the strengths individuals possess and maximise the effect of protective factors present in patients' environment. Also, when balancing pros and cons of a possible psychiatric admission, we need to remember that especially in the case of affective and psychotic disorders, the week after hospitalisation and the week following discharge is when suicide risk is at the highest level [29].

It is imperative, then, to ensure that the management of suicide risk and the treatment of any underlying mental illness occur within the individuals' social context and family environment in order to promote resilience and take advantage of the support already available in the community [66]. If hospitalisation is identified as the most appropriate course of action, it is important to make sure that the patient and his/her carers participate in the decision-making process and are aware of the objectives clinicians are trying to achieve. It is also fundamental to establish an appropriate level of monitoring during the inpatient stay to reflect the intensity of suicide risk at the different stages of treatment. Standard safety precautions should be always implemented to identify and remove from the patient and the hospital environment anything that can be used to self-harm or attempt suicide. As already highlighted, in applying these strategies we must always ensure individuals are treated with the least restrictive means. On rare occasions, the level of suicide risk and/or the level of uncooperativeness the patient displays will be so high that involuntary inpatient treatment becomes the only viable option. In those occasions we have to accept a potential strain to the therapeutic alliance in order to ensure the safety of the patient. The reasons for enforcing hospital treatment and not using other treatment options should be documented, and a clear treatment plan should be outlined so that the involuntary status is not unduly prolonged. Clinicians should remember that if the patient is determined to die by suicide, no much can be done to avert it. In a review of inpatient suicides, it was found that majority of the 76 suicides studied were on close observation or even with staff members at the time of suicide [67].

If the decision is made that the patient can be safely treated as an outpatient, the clinician's focus will need to shift towards maximising the beneficial effect of all the protective factors identified during the assessment. Clini- 
cians also need to be mindful of the fact that the stronger the therapeutic alliance with the patient is, the higher the chances of reducing suicidality will be. Flexibility in the delivery of outpatient services is required in addressing such difficult circumstances, and clinicians have to be ready to increase the frequency of appointments, as well as instituting planned telephone contacts between consultations. Medication should also be reviewed, and appropriate steps should be takensuch as: monitoring and ensuring compliance, adding or increasing the dosage of certain medications to counteract the impact of possible distressing symptoms, and restricting access to large amounts of medication to reduce patient's access to means of suicide or self harm. In regard to the latter, every possible effort should be made-with the cooperation of family and carers - to remove all potential means of suicidefrom the patient's environment.

\subsection{Psychological Approaches}

Psychotherapies represent a valuable tool in the treatment and management of suicide risk. Even though none of the current approaches utilised in clinical practice has been identified as "the approach" able to prevent suicide, many of them have been found to significantly contribute to the reduction of suicide and self harm risk. The task of researching the efficacy of psychotherapy in suicide prevention is often made arduous by the ethical restrictions imposed on the study of individuals at risk of suicide. Another difficulty in studying different types of psychotherapeutic approaches is that of ensuring absolute adherence to the model of treatment by therapists involved in the research process. In fact, the impact of factors such as the warmth of the therapeutic relationship can significantly impact on outcomes of a given psychotherapeutic approach. Despite the above limitations, research in the field has produced some useful data that we can transfer into every day clinical practice.

Structured problem-solving, for example, is one mode of intervention that has been found useful in the management of deliberate self-ham. Even tough studies conducted so far have provided conflicting evidence regarding its impact on repetition of DSH, there are promising data regarding the impact of such approach on several of the risk factors for deliberate self-harm. A meta-analysis of randomized controlled trials showed that offering individuals with a recent episode of deliberate self harm a course of problem solving training not only increased individuals' ability to reduce the impact of stressors, but also resulted in a reduction in levels of hopelessness and depression [68]. When it comes to more complex modes of intervention requiring clinicians to undergo more intensive training and supervision, research into cognitive therapy and interpersonal therapy has also produced promising results, especially in regard to retention and com- pliance with treatment $[69,70]$.

In the case of individuals presenting with Borderline Personality Disorder (where psychological treatment is still recognized as the mainstay of any management plan), dialectical behaviour therapy (DBT) has been shown to produce significant reduction in the rate of repetition of deliberate self-harm, suicide ideation and hospitalizetions [71]. Research on the treatment of individuals with Borderline Personality Disorder has recently produced interesting data on novel approaches, such as mentalization-based treatment with reduction in both suicidality and mental health services utilization [72].

Despite growing interest and research into the psychosocial treatment of suicidal behaviour, we are still a long way from being able to develop an effective and userfriendly approach that can reliably and consistently reduce suicidality in individuals at risk. In fact, larger and better-controlled trials are needed in order to produce reliable data we can confidently implement in clinical practice [73].

\subsection{Biological Approaches}

Notwithstanding the multitude of pharmacological agents currently available to clinicians, lithium is still the medication with the most evidence on its efficacy in the treatment of suicidality. When administered for the maintenance treatment of bipolar affective disorder, data show a suicide rate around eight times lower than in individuals whose treatment did not include lithium. It has also been observed that the beneficial impact on suicidality is not necessarily related to the mood stabilizing effect lithium has on bipolar patients [74]. More recently, evidence has emerged to support the use of lithium also in the treatment of depressive illness regardless of the presence of bipolar disorder. In a meta-analysis, the authors found that in individuals with recurrent major depressive disorder treated with lithium, the reduction in suicide rate was very close to the one observed in the bipolar population [75]. The risk of significant side effects and toxicity has so far been the main barrier hindering a more widespread use of lithium as a standard treatment of suicidality, especially when prescribed for women in child-bearing age. As a result, it has been observed that despite the overwhelming evidence produced over the years, there has been a progressive reduction in the prescription of such compounds [76].

A similar scenario is observed in the case of clozapine, an antipsychotic used for the treatment of schizophrenia, the beneficial effect of which on suicidality has been established in a number of high quality studies. One of the most cited is the InterSePT study, a multicentre, randomized, international study in which the authors followed up for two years 980 patients with schizophrenia or schizoaffective disorder at high suicide risk. Patients treated 
with clozapine were found to have a lower rate of suicide attempts and hospitalisations, and were less likely to require additional medication such as antidepressants or anxiolytics [77]. Moreover, it has been demonstrated that the reduction in suicide rates for schizophrenia patients is independent from the action on the psychotic symptoms individuals presented with [35]. However, as observed in the case of lithium treatment, the risk of potentially lethal adverse events with clozapine treatment has hindered a wider utilisation of this very effective agent. The risk of neutropenia and cardiotoxicity has in fact made it necessary to enforce very strict protocols of administration and monitoring. The end result-in many countries around the world-has been that clozapine can only be prescribed as second or third line of treatment by specialised clinical centres [78].

Electroconvulsive therapy (ECT) is another treatment modality often used to reduce suicidality in individuals affected by either psychotic or mood disorders. It is particularly valuable when other treatments have failed or when the use of psychotropic medication is contraindicated, such as in the case of pregnant women or certain medical conditions. It is of note that the impact ECT has on suicidality is particularly rapid. In fact, a study by [79] on 131 individuals presenting with suicide ideation, showed that by week 2 (after 6 ECT sessions) almost two thirds of the patients reported a significant reduction in suicidality.

The role of antidepressants medication treatment in the prevention of suicide appears to be even more complex. Much research has been produced to try to elucidate whether the more widespread use of compounds such as the SSRI's (selective serotonin re-uptake inhibitors) had any clear impact on suicidal behaviour. The controversy culminated in 2004, when in the US the Food and Drug Administration made a request to drug manufacturing companies to include a black-box warning of increased risk of suicide for children and adolescent with major depressive disorders and other psychiatric disorders. The following year, the same recommendation was made for SSRI medication prescribed to the adult population [80]. In particular, the recommendation was to closely monitor patient commenced on SSRI's in the first few weeks of treatment to assess the emergence of increased suicidality. Since then, there have been numerous attempts to verify the validity of such warning. A number of meta-analyses have been conducted focusing on the occurrence of suicidal behaviour in individuals treated with SSRI's. Many of them report a link even if not strong, between the use of SSRI's and suicidal behaviour in children and the adolescent population [81,82]. In the studies considering the adult population the findings are even less clear. A study focusing on the impact of the wider use of antidepressants in Northern Europe during the 90's, found that in many of the countries researched the suicide rate was already declining at the time of the introduction of SSRI's [83,84]. In a metaanalysis conducted utilizing drug company data on 40,000 individuals in 477 randomised controlled trials, the authors found no link between SSRI's use and suicide rates. In the same study, some evidence was found for an increased incidence of non-fatal suicidal behaviour during treatment [85].

\section{CONCLUSION}

Dealing with suicidal patients represents a challenging clinical task, which requires competence and dedication. Apart from knowledge of protocols and therapeutic tools, clinicians are particularly requested to care. Being perceived by the suicidal patient as an insufficiently caring professional might constitute the last ring of a long chain of disappointments.

\section{REFERENCES}

[1] De-Leo, D., Burgis, S., Bertolote, J.M., Kerkhof, A.J.F.M. and Bille-Brahe, U. (2006) Definitions of suicidal behaviour: Lessons learned from the WHO/EURO multicentre study. Crisis, 27, 4-15. doi:10.1027/0227-5910.27.1.4

[2] Silverman, M.M., Berman, A.L., Sanddal, N.D., O’Carroll, P.W. and Joiner, T.E. (2007) Rebuilding the tower of babel: A revised nomenclature for the study of suicide and suicide-related behaviours. Suicide and Life-Threatening Behavior, 37, 264-277.

doi:10.1521/suli.2007.37.3.248

[3] Hawton K. and van Heeringen K. (2002) The International Handbook of Suicide and Attempted Suicide. Wiley, Chichester.

[4] De-Leo, D. (2011) DSM-V and the future of suicidology. Crisis, 32, 233-239. doi:10.1027/0227-5910/a000128

[5] Cooper, J., Kapur, N., Webb, R., Lawlor, M., et al. (2005) Suicide after deliberate self-harm: A 4-year cohort study. American Journal of Psychiatry, 162, 297-303. doi:10.1176/appi.ajp.162.2.297

[6] De-Leo, D., Cerin E., Spathonis, K. and Burgis, S. (2005) Lifetime risk of suicide ideation and attempts in an Australian community: Prevalence, suicidal process, and helpseeking behaviour. Journal of Affective Disorders, 86, 215-225. doi:10.1016/j.jad.2005.02.001

[7] Milner, A. and De-Leo, D. (2010) Who seeks treatment where? Suicidal behaviors and health care: Evidence from a community survey. Journal of Nervous and Mental Disease, 198, 412-419. doi:10.1097/NMD.0b013e3181e07905

[8] World Health Organization (2005) Suicide huge but preventable public health problem. http://www.who.int/mediacentre/news/releases/2004/pr61 len/

[9] Diekstra, R.F.W., Gulbinat, W., Kienhorst, I. and De-Leo, 
D. (1995) Preventive Strategies on Suicide. Vol. 2. Copublication WHO, Geneva \& E.J. Brill, Leiden/New York/Koln.

[10] Bertolote, J.M., Fleischmann, A., De-Leo, D., Bolhari, J., Botega, N., De Silva, E., Huong, T.T.T., Phillips, M., Schlebusch, L., Varnik, A., Vijayakumar, L. and Wasserman, D. (2005) Suicide attempts, plans, and ideation in culturally diverse sites: The WHO SUPRE-MISS community survey. Psychological Medicine, 35, 1457-1465. doi:10.1017/S0033291705005404

[11] American Psychiatric Association (2003) Practice guidelines for the assessment and treatment of suicidal behaviour. American Journal of Psychiatry, 160, 1-60.

[12] National Institute for Clinical Excellence (2004) Selfharm: The short-term physical and psychological management and secondary prevention of self-harm in primary and secondary care. National Institute for Clinical Excellence, London.

[13] American Psychiatric Association (2000) Diagnostic and statistical manual of mental disorders, 4th Edition TR. American Psychiatric Association, Washington, DC.

[14] American Academy of Child and Adolescent Psychiatry (2001) Summary of the practice parameters for the assessment and treatment of children and adolescents with suicidal behaviours. Journal of the American Academy of Child and Adolescent Psychiatry, 40, 495-499. doi:10.1097/00004583-200104000-00024

[15] De-Leo, D., Bertolote, J.M. and Lester, D. (2002) Self directed violence. In: Krug, E.G., Dahlberg, L.L., Mercy, J.A., et al. Eds., World Report on Violence and Health, World Health Organisation, Geneva, 185-212.

[16] Brent, D.A. and Mortiz, G. (1996) Developmental pathways to adolescent suicide. In: Cichetti, D. and Toth, S., Eds., Adolescents: Opportunities and challenges. University of Rochester Press Rochester, New York.

[17] World Health Organization (2002) Distribution of suicide rates (per 100,000) by gender and age, 2000. http://www.who.int/mental_health/prevention/suicide/sui cide_rates_chart/en/

[18] Wyder, M., Ward, P. and De-Leo, D. (2009) Separation as a suicide risk factor. Journal of Affective Disorders, 116, 208-213. doi:10.1016/j.jad.2008.11.007

[19] Kolves, K., Ide, N. and De-Leo, D. (2011) Marital breakdown, shame and suicidality in men: A direct link? Suicide and Life-Threatening Behavior, 41, 149-159. doi:10.1111/j.1943-278X.2011.00021.X

[20] Cantor, C.H. and Slater P.J. (1995) Marital breakdown, parenthood and suicide. Journal of Family Studies, 1, 91102. doi:10.5172/jfs.1.2.91

[21] Qin, P., Agerbo, E. and Mortensen, P.B. (2002) Suicide risk in relation to socioeconomic, demographic, psychiatric, and familial factors: A national register-based study of all suicides in Denmark, 1981-1997. American Journal of Psychiatry, 160, 765-772. doi:10.1176/appi.ajp.160.4.765

[22] Runeson, B. and Asberg, M. (2003) Family history of suicide among suicide victims. American Journal of Psychiatry, 160, 1525-1526.

\section{doi:10.1176/appi.ajp.160.8.1525}

[23] Roy, A. (2006) Family history of suicide and impulsivity. Archives of Suicide Research, 10, 347-352. doi:10.1080/13811110600790983

[24] De-Leo, D. and Krysynska, K. (2008) Suicide and selfdirected violence. In: Heggenhougen, K. and Quah, S., Eds., International Encyclopedia of Public Health, Academic Press, San Diego, 267-275.

[25] Gibb, S.J., Beautrais, A.L. and Fergusson, D.M. (2005) Mortality and further suicidal behaviour after an index suicide attempt: A 10-year study. Australian and New Zealand Journal of Psychiatry, 39, 95-100. doi:10.1080/j.1440-1614.2005.01514.X

[26] Beck, A.T., Brown, G.K., Steer, R.A., Dahlsgaard, K.K. and Ggrisham, J.R. (1999) Suicide ideation at its worst point: A predictor of eventual suicide in psychiatric outpatients. Suicide \& Life-Threatening Behavior, 29, 1-9.

[27] Johannessen, H.A., Dieserud, G., Jakhelln, F., Zahl, P.H. and De-Leo, D. (2009) Changes in institutional psychiatric care and suicidal behaviour: A follow-up study of inpatient suicide attempters in Baerum, Norway. Social Psychiatry and Psychiatric Epidemiology, 44, 845-851. doi:10.1007/s00127-009-0006-8

[28] Hoyer, E.H., Olesen, A.V. and Mortensen, P.B. (2004) Suicide risk in patients hospitalised because of an affective disorder: A follow-up study, 1973-1993. Journal of Affective Disorders, 78, 209-217. doi:10.1016/S0165-0327(02)00311-7

[29] Qin, P. and Nordentoft, M. (2005) Suicide risk in relation to psychiatric hospitalization. Archives of General Psychiatry, 62, 427-432. doi:10.1001/archpsyc.62.4.427

[30] De-Leo, D. and Heller, T. (2007) Intensive case management in suicide attempters following discharge from inpatient psychiatric care. Australian Journal of Primary Health, 13, 49-59. doi:10.1071/PY07038

[31] Wasserman, D. (2001) Suicide. An Unnecessary Death, Dunitz, London.

[32] World Health Organization (2000) Preventing Suicide: A resource for general physicians. WHO, Geneva.

[33] Bertolote, J.M., Fleischmann, A., De-Leo, D. and Wasserman, D. (2003) Suicide and mental disorders: Do we know enough? (Editorial) British Journal of Psychiatry, 183, 382-383. doi:10.1192/bjp.183.5.382

[34] De-Leo, D. (2009) Cross-cultural research widens suicide prevention horizons (Editorial). Crisis, 30, 59-62. doi:10.1027/0227-5910.30.2.59

[35] De-Leo, D. and Spathononis, K. (2003) Do psychopharmacological and psychosocial treatments reduce suicide risk in schizophrenia and schizophrenia spectrum disorders? Archives of Suicide Research, 7, 354-373. doi:10.1080/713848945

[36] Linehan, M.M., Goodstein, J.L., Nielsen, S.L., et al. (1983) Reasons for staying alive when you are thinking of killing yourself: The rasons for living inventory. Journal of Consulting and Clinical Psychology, 51, 276-286. doi:10.1037/0022-006X.51.2.276

[37] Hendin, H., Haas, A.P. and Maltsberger, J.T. (2006) 
Problems in psychotherapy with suicidal patients. American Journal of Psychiatry, 163, 67-72. doi:10.1176/appi.ajp.163.1.67

[38] Jacobs, D. (1989) Psychotherapy with suicidal patients: The empathic method. In: Jacobs, D., Brown, H.N. Eds., Suicide: Understanding and Responding. International Universities, Madison, 329-342.

[39] Simon R.I. (2002) Suicide risk assessment: What is the standard of care? Journal of the American Academy of Psychiatry and Law, 30, 340-344.

[40] Simon, R.I. (2004) Assessing and Managing Suicide Risk: Guidelines for Clinical Risk Management. American Psychiatric Publishing, Arlington.

[41] Harris, C.E. and Barraclough B. (1997) Suicide as an outcome for mental disorders. British Journal of Psychiatry, 170, 205-228. doi:10.1192/bjp.170.3.205

[42] Oquendo, M.A., Currier, D. and Mann, J.J. (2006) Prospective studies of suicidal behavior in major depressive and bipolar disorders: What is the evidence for predictive risk factors? Acta Psychiatrica Scandinavica, 114, 151158. doi:10.1111/j.1600-0447.2006.00829.x

[43] Smith, J.M., Alloy, L.B. and Abramson, L.Y. (2006) Cognitive vulnerability to depression, rumination, hopelessness, and suicidal ideation: multiple pathways to selfinjurious thinking. Suicide and Life Threatening Behavior, 36, 443-454. doi:10.1521/suli.2006.36.4.443

[44] Beck, A.T., Steer, R.A., Kovacs, M., et al. (1985) Hopelessness and eventual suicide: A 10-year prospective study of patients hospitalized with suicidal ideation. American Journal of Psychiatry, 142, 559-563.

[45] Isometsa, E. (2005) Suicide in bipolar I disorder in Finland: Psychological autopsy findings from the National Suicide Prevention Project in Finland. Archives of Suicide Research, 9, 251-260. doi:10.1080/13811110590929442

[46] Palmer, B.A., Pankratz, S. and Bostwick, J.M. (2005) The lifetime suicide risk in schizophrenia. Archives of General Psychiatry, 62, 247-253.

[47] Hawton, K. and James, A. (2005) Suicide and deliberate self-harm in young people. British Medical Journal, 330, 891-894. doi:10.1136/bmj.330.7496.891

[48] Murphy, G.E. (2002) Psychiatric aspects of suicidal behaviour: Substance abuse. In: Hawton K., van Heeringen K., Eds., The International Handbook of Suicide and Attempted Suicide, Wiley, Chichester.

[49] Rossow, I. and Amundsen, A. (1995) Alcohol abuse and suicide: A forty year prospective study of Nerwegian conscripts. Addiction, 90, 685-691. doi:10.1111/j.1360-0443.1995.tb02206.x

[50] Sher L. (2006) Alcoholism and suicidal behavior: A clinical overview. Acta Psychiatrica Scandinavica, 113, 13-22. doi:10.1111/j.1600-0447.2005.00643.x

[51] Gerson, J. and Stanley, B. (2002) Suicidal and self-injurious behaviour in personality disorder: Controversies and treatment directions. Current Psychiatry Reports, 4, 30-38. doi:10.1007/s11920-002-0009-6

[52] Isometsa, E.T. (2001) Psychological autopsy studies: A review. European Psychiatry, 16, 379-384.

\section{doi:10.1016/S0924-9338(01)00594-6}

[53] Schmidtke, A., Bille-Brahe, U., De-Leo, D., et al. (2004) Sociodemographic characteristics of suicide attempters in Europe: Combined results of the monitoring part of the WHO/EURO multicentre study on suicidal behaviour. In: Schmidtke, A., Bille-Brahe, U., De-Leo, D. and Ker- khof, A. Eds., Suicidal Behaviour in Europe: Results from the WHO/EURO Multicentre Study on Suicidal Behaviour. Hogrefe \& Huber, Göttingen, 29-43.

[54] Krysinska, K., Heller, T.S. and De-Leo, D. (2006) Suicide and deliberate self-harm in personality disorders. Current Opinion in Psychiatry, 19, 95-101. doi:10.1097/01.yco.0000191498.69281.5e

[55] Kessler, R., Berglund, P., Demler, O., et al. (2005) Lifetime prevalence and age-of-onset distributions of DSMIV disorders in the National Comorbidity Survey Replication. Archives of General Psychiatry, 62, 593-602. doi:10.1001/archpsyc.62.6.593

[56] Hawgood, J., Spathonis, K. and De-Leo, D. (2004) Physical illness and suicidal behaviour. In: De-Leo, D., BilleBrahe, U., Kerkhof, A.D.J.F. and Schmidtke, A., Eds., Suicidal Behaviour: Theories and Research Findings. Hogrefe and Huber, Göttingen, 139-164.

[57] Madge, N., Hawton, K., McMahon, E., Corcoran, P., De-Leo, D., De Wilde, E.J., Fekete, S., Van Heeringen, C., Ystgaard, M. and Arensman, E. (2011) Psychological characteristics, stressful life events and deliberate-selfharm: Findings from the child and adolescent self-harm in Europe (CASE) study. European Child and Adolescent Psychiatry, 20, 499-508. doi:10.1007/s00787-011-0210-4

[58] Scoliers, G., Portzky, G., Madge, N., Hewitt, A., Hawton, K., De Wilde, E.J., Ystgaard, M., Arensman, E., De-Leo, D., Fekete, S. and Van Heeringen, C. (2009) Reasons for adolescent deliberate self-harm: A cry of pain and/or a cry for help? Findings from the child and adolescent self-harm in Europe (CASE) study. Social Psychiatry and Psychiatry Epidemiology, 44, 601-607. doi:10.1007/s00127-008-0469-z

[59] Mann, J.J., Apter, A., Bertolote, J., Beautrais, A., Currier, D., Haas, A., Hegerl, U., Lonnqvist, J., Malone, K., Marusic, A., Mehlum, L., Patton, G., Phillips, M., Rutz, W., Rihmer, Z., Schmidtke, A., Shaffer, D., Silverman, M., Takahashi, Y., Varnik, A., Wasserman, D., Yip, P. and Hendin, H. (2005) Suicide prevention strategies. A systematic review. Journal of the American Medical Association, 294, 2064-2074. doi:10.1001/jama.294.16.2064

[60] De-Leo, D. and Diekstra, R.F.W. (1990) Depression and Suicide in Late Life. Hogrefe/Huber, Toronto/Bern.

[61] Erlangsen, A., Nordentoft, M., Conwell, Y., Waern, M., De-Leo, D., Lindner, R., Oyama, H., Sakashita, T., Andersen-Ramberg, K., Quinnet, P., Draper, B., Lapierre, S. and the International Research Group on Suicide Among the Elderly (2011) Key considerations for preventing suicide in older adults: Consensus opinions of an expert panel. Crisis, 32, 106-109. doi:10.1027/0227-5910/a000053

[62] Hawton, K. and Harriss, L. (2006) Deliberate self-harm in people aged 60 years and over: Characteristics and outcome of a 20-year cohort. International Journal of Geri- 
atric Psychiatry, 21, 572-581. doi:10.1002/gps.1526

[63] De-Leo, D. and Scocco, P. (2000) Treatment and prevention of suicidal behaviour in the elderly. In: Hawton, K. and Van Heeringen, K., Eds., The International Handbook of Suicide and Attempted Suicide, Wiley, Chichester, 555-570. doi:10.1002/9780470698976.ch31

[64] Gabbard, G.O. and Allison, S.E. (2006) Psychodynamic treatment. In: Simon, I. and Hales, R.E. Eds., Textbook of Suicide Assessment and Management. American Psychiatric Publishing, Washington DC, 221-234.

[65] Simon, R.I. (2006) Patient safety versus freedom of movement: Coping with uncertainty, In: Simon, R.I. and Hales, R.E., Eds., Textbook of Suicide Assessment and Management. American Psychiatric Publishing, Washington DC, 423-439.

[66] Bille-Brahe, U. and Jensen, B. (2004) The importance of social support. In: De-Leo, D., Bille-Brahe, U., Kerkhof, A.D.J.F. and Schmidtke A., Eds., Suicidal behaviour. Theories and research findings, Hogrefe and Huber, Göttingen, 197-208.

[67] Fawcett, J., Busch, K.A. and Jacobs, D.G. (2003) Clinical correlates of inpatient suicide. Journal of Clinical Psychiatry, 64, 14-19. doi:10.4088/JCP.v64n0105

[68] Townsend, E., et al. (2001) The efficacy of problemsolving treatments after deliberate self-harm: Meta-analysis of randomized controlled trials with respect to depression, hopelessness and improvement in problems. Psychological Medicine, 31, 979-988. doi:10.1017/S0033291701004238

[69] Brown, G.K., Ten Have, T.R., Henriques, G.R., et al. (2005) Cognitive therapy for the prevention of suicide attempts: A randomized controlled trial. Journal of the American Medical Association, 294, 563-570. doi:10.1001/jama.294.5.563

[70] Guthrie, E., Kapur, N., Mackway-Jones, K., et al. (2001) Randomised controlled trial of brief psychological intervention after deliberate self poisoning. British Medical Journal, 323, 135-138. doi:10.1136/bmj.323.7305.135

[71] Linehan, M.M., Comtois, K.A., Murray, A.M., Brown, M.Z., Gallop, R.J., Heard, H.L., Korslund, K.E., Tutek, D.A., Reynolds, S.K. and Lindenboim, N. (2007) Twoyear randomized controlled trial and follow-up of dialectical behaviour therapy by experts for suicide-related behaviours and borderline personality disorder. Archives of General Psychiatry, 63, 757-766. doi:10.1001/archpsyc.63.7.757

[72] Bateman, A. and Fonagy, P. (2008) 8-year follow-up of patients treated for bosrderline personality disorder: Mentalisation-based treatment versus treatment as usual. American Journal of Psychiatry, 165, 631-638. doi:10.1176/appi.ajp.2007.07040636

[73] Crawford, M.J., Thomas, O., Khan, N. and Kulinskaya, E. (2007) Psychosocial interventions following self-harm: Systematic review of their efficacy in preventing suicide. British Journal of Psychiatry, 190, 11-17.

\section{doi:10.1192/bjp.bp.106.025437}

[74] Müller-Oerlinghausen, B., Felber, W., Berghöfer, A., Lauterbach, E. and Ahrens, B. (2005) The impact of lithium long-term medication on suicide-related behaviours and mortality of bipolar patients. Archives of Suicide Research, 9, 307-319. doi:10.1080/13811110590929550

[75] Guzzetta, F., Tondo, L., Centorrino, F. and Baldessarini, R.J. (2007) Lithium treatment reduces suicide risk in recurrent major depressive disorder. Journal of Clinical Psychiatry, 68, 380-383. doi:10.4088/JCP.v68n0304

[76] Young, A.H. and Hammond, J.M. (2007) Lithium in mood disorders: Increasing evidence base, declining use? British Journal of Psychiatry, 191, 474-476. doi:10.1192/bjp.bp.107.043133

[77] Meltzer, H.Y., Alphs, L., Green, A.I., Altamura, A.C., Anand, R., Bertoldi, A., Bourgeois, M., Chouinard, G., Islam, M.Z., Kane, J., Krishnan, R., Lindenmayer, J.P. and Potkin, S. (2003) Clozapine treatment for suicidality in schizophrenia: International Suicide Prevention Trial Study Group (InterSePT). Archives of General Psychiatry, 60, 82-91. doi:10.1001/archpsyc.60.1.82

[78] Wahlbeck, K., Cheine, M. and Essali, M.A. (2000) Clozapine versus typical neuroleptic medication for schizophrenia. Cochrane Database of Systematic Reviews, 2, CD000059.

[79] Kellner, C.H., Fink, M., Knapp, R., et al. (2005) Relief of expressed suicidal intent by ECT: A consortium of research in ECT study. American Journal of Psychiatry, 162, 977-982. doi:10.1176/appi.ajp.162.5.977

[80] Food and Drug Administration (2005) Reviews data for antidepressant use in adults.

http://www.fda.gov/bbs/topics/ANSWERS/2005/ANS01 362.html

[81] Dubicka, B., Hadley, S. and Roberts, C. (2006) Suicidal behaviour in youths with depression treated with newgeneration antidepressants: Mata-analysis. British Journal of Psychiatry, 189, 393-398. doi:10.1192/bjp.bp.105.011833

[82] Hammad, T.A., Laughren, T. and Racoosin, J. (2006) Suicidality in pediatric patients treated with antidepressant drugs. Archives of General Psychiatry, 63, 332-339. doi:10.1001/archpsyc.63.3.332

[83] Bray, I. and Gunnell, D. (2006) Relationship between antidepressant sales and secular trends in suicide rates in the Nordic countries. British Journal of Psychiatry, 188, 354-358. doi:10.1192/bjp.188.4.354

[84] Zahl, P., De-Leo, D., Ekeberg, O., Hjelmeland, H. and Dieserud, G. (2010) The relationship between sales of SSRI, TCA and suicide rates in Nordic countries. BMC Psychiatry, 10, 1-9.

[85] Gunnell, D., Saperia, J. and Ashby, D. (2005) Selective serotonin reuptake inhibitors (SSRIs) and suicide in adults: Meta-analysis of drug company data from placebo controlled, randomised controlled trials submitted to the MHRA's safety review. British Medical Journal, 19, 1-5. 